\title{
Western Canadiana Publications Project Bibliography
}

\author{
Gloria M. Strathern
}

BECAUSE THE WESTERN CANADIANA PUBLICATIONS PROJECT'S BIBLIOgraphical undertaking is still very much in the planning rather than the production phase, I propose to report very briefly on progress to date.

As announced in Newsletter no. I in April 1977, the Project proposed to devote the December issue to a bibliography of the past year for Western Canadian items, with some backtracking, so that eventually an update of Bruce Peel's Bibliography of the Prairie Provinces would be produced from I954. I offered to help in this work last January.

As a first step, Mrs. Catherine Wang, a Faculty of Library Science student, compiled a test file of 1976 Alberta Publications from Canadiana and the list of Alberta books compiled for the Letter of the LAA by Mrs. Maureen Bradbury of the University of Alberta Library's Special Collections Division. This provides some information about the range of subject and possible size of the project.

A basic bibliography of Prairie bibliographies has been compiled. I have also spent time talking to interested people about the project in order to learn who is working in the field, who is interested in the project, and what kind of information they have.

I have also been working on establishing a format for bibliographic entries. The sPIREs (Standford Public Information Retrieval System) program is available at the University of Alberta and has already been used for the Alberta Government Publications Project (GAP) and the Boreal Institute's Yukon Bibliography. It offers a very versatile program suitable for generating various checklists as well as a facility to update the bibliography with the minimum of duplication of records. We propose to use the sPIREs system to produce the bibliography.

Some time has also been devoted to developing guidelines for inclusion and exclusion. It is now proposed that the initial bibliography should constitute a comprehensive coverage of Alberta-related monographic publications in the humanities and the social sciences. Entries will have brief annotations, and indexes will include a chronological file, titles, subjects, publishers and place 
of publication. It will include publications in languages other than French and English.

Determining what constitutes an 'Alberta-related' publication and who qualifies as an 'Alberta author' will present problems.

I perceive that the biggest problems will be time, staff, and money, which will surprise nobody here today. Time will be the most serious problem. However, if some of the proposed financial assistance is forthcoming, that too can be dealt with.

I have not gone into any details about methods, because that would be a little premature. However, I will be glad to answer any questions. I will be even more glad to receive any suggestions, recommendations and offers of assistance. 